\title{
Abundance estimates for management of endangered false killer whales in the main Hawaiian Islands
}

\author{
Amanda L. Bradford ${ }^{1, *}$, Robin W. Baird ${ }^{2}$, Sabre D. Mahaffy ${ }^{2}$, \\ Antoinette M. Gorgone ${ }^{2}$, Dan J. McSweeney ${ }^{3}$, Tori Cullins ${ }^{4}$, Daniel L. Webster ${ }^{2}$, \\ Alex N. Zerbini ${ }^{2}$ \\ ${ }^{1}$ Pacific Islands Fisheries Science Center, NMFS, NOAA, 1845 Wasp Boulevard, Building 176, Honolulu, HI 96818, USA \\ ${ }^{2}$ Cascadia Research Collective, 218 $1 / 2$ West 4th Avenue, Olympia, WA 98501, USA \\ ${ }^{3}$ Wild Whale Research Foundation, Box 139 Holualoa, HI 96724, USA \\ ${ }^{4}$ Wild Dolphin Foundation, 1850 Worthington Road, Eagle Point, OR 97524, USA
}

\begin{abstract}
Effectively using the best available data to meet management mandates for endangered populations is a common conservation challenge. False killer whales Pseudorca crassidens occur as 3 distinct populations in Hawaiian waters, including a resident main Hawaiian Islands (MHI) population that is endangered under the US Endangered Species Act. A longitudinal, photo-identification dataset of 171 distinctive individuals and open mark-recapture methods were used to estimate current MHI false killer whale abundance as needed for management of this population. The data are from dedicated and opportunistic surveys conducted from 2000 to 2015 around the MHI and reflect unquantified spatiotemporal biases imposed by necessary sampling constraints. Accounting for temporal variation and especially social group affiliation was important in modeling capture probability. Sensitivity analyses found that the resulting time series of 16 abundance estimates is robust to some forms of sampling variability and bias. However, because the study area was partially sampled each year, the annual abundance estimates apply only to the portion of the population using the sampled area and may underestimate true population abundance. Nonetheless, the resulting estimates and supporting evidence indicate that the MHI false killer whale population is relatively small; for example, only 167 ( $\mathrm{SE}=23,95 \% \mathrm{CI}=128-218$ ) individuals were estimated to have used the sampled area in 2015. Until data are available to estimate or overcome sampling biases, this estimation framework offers a tool for using data that have been regularly collected each year to produce current abundance estimates that are improvements over existing management inputs.
\end{abstract}

KEY WORDS: Conservation - Management $\cdot$ Abundance $\cdot$ Mark-recapture $\cdot$ False killer whale $\cdot$ Hawaii $\cdot$ Photo-identification $\cdot$ POPAN

\section{INTRODUCTION}

Monitoring endangered populations for conservation and management requires data that can be especially difficult to collect if the populations are rare, cryptic, or inaccessible. Resulting data deficiencies pose challenges to scientists and managers

\footnotetext{
${ }^{*}$ Corresponding author: amanda.bradford@noaa.gov
}

involved in the recovery of these populations. These specialists are usually mandated to proceed using the best available data, although what constitutes such data is not always clear. Existing guidance generally emphasizes accounting for bias and uncertainty in the data that are used and acknowledging the limits of inferences that can be

(C) The authors 2018 and, outside the USA, the US Government. Open Access under Creative Commons by Attribution Licence. Use, distribution and reproduction are unrestricted. Authors and original publication must be credited. 
made from them (e.g. Joly et al. 2010, Murphy \& Weiland 2016).

The false killer whale Pseudorca crassidens is a tropical and warm temperate oceanic species that is broadly distributed, but naturally rare throughout its range (Baird 2018). Although false killer whales are generally found in the open ocean, they can use shallow waters close to shore (Acevedo-Gutierrez et al. 1997, Weir et al. 2013, Zaeschmar et al. 2014, Palmer et al. 2017) and form island-associated populations (Baird et al. 2008, 2013a). Most of what is known about false killer whale ecology has come from a long-term study, initiated in 2000, of an island-associated population in the Hawaiian Archipelago (Baird et al. 2008, 2010). This population is resident to the main Hawaiian Islands (MHI) and has been found to associate preferentially in at least 3 social groups or 'clusters' (Baird et al. 2012). The MHI insular population is 1 of 3 false killer whale populations in Hawaiian waters and has been differentiated from the lesser-known pelagic and island-associated Northwestern Hawaiian Islands populations using genetic, photo-identification, and movement data (Chivers et al. 2007, Baird et al. 2008, 2010, 2013a, Chivers et al. 2010, Martien et al. 2014).

Considering a precipitous decline in recent decades and evidence of multiple threats, the MHI false killer whale population was listed as endangered under the US Endangered Species Act (ESA) in 2012. 1 This decline was based on decreasing false killer whale sighting rates during systematic aerial surveys of the MHI from 1993 to 2003 (Mobley 2004, J. R. Mobley et al. unpubl.), as well as observations of 3 groups of false killer whales during aerial surveys in 1989 (Reeves et al. 2009) that were each approximately 3 times larger than the best available estimate of population size at the time of the ESA Status Review (Oleson et al. 2010). While there was no reason to doubt the magnitude of the abundance estimate used in the ESA Status Review (Oleson et al. 2010), which suggested the population numbered around 150 individuals, the estimate was based on data and analytical methods that were undergoing refinement. An updated and more rigorous estimate of MHI false killer whale abundance would inform the development and implementation of an ESA Recovery Plan. ${ }^{2}$

The management scheme established by the US Marine Mammal Protection Act (MMPA) also requires an estimate of abundance to calculate the

177 Federal Register 70915 (28 November 2012), www.gpo. gov/fdsys/granule/FR-2012-11-28/2012-28766

$\underline{2} 78$ Federal Register 60850 (2 October 2013), www.gpo.gov/ fdsys/granule/FR-2013-10-02/2013-24049 potential biological removal (PBR), which is the maximum level of human-caused mortality that can be removed annually from each management stock. A PBR is calculated for all known stocks and presented in stock assessment reports (SARs) that are mandated by the MMPA. The specific abundance input into the PBR equation is the minimum population estimate $\left(N_{\min }\right)$, which the MMPA specifies should reflect the best available scientific information, incorporate uncertainty, and provide assurance that the stock is at least the size of the estimate. Operationally, the goals of the MMPA can be achieved by defining $N_{\min }$ as the 20th percentile of a log-normal distribution based on an abundance estimate (Wade 1998). Given their endangered status, MHI false killer whales are a strategic stock under the MMPA, which means that their SAR should be reviewed annually. Current estimates of MHI false killer whale abundance would allow for a more precise assessment of the implications of any human-caused mortality relative to PBR during these reviews.

The ongoing, long-term study of MHI false killer whales has resulted in a longitudinal dataset of photo-identified individuals that can be used for mark-recapture abundance estimation (Baird et al. 2008). Previous mark-recapture abundance estimates have been made from these data (Baird et al. 2005, Oleson et al. 2010), but were not used to determine $N_{\min }$ in associated SARs because known biases in the estimates were not addressed. Further, the analytical methods that were used produced abundance estimates that spanned multi-year periods, making the estimates difficult to interpret and incorporate into the annual framework of the stock assessment process. Instead, values of $N_{\min }$ for MHI false killer whales have been based on catalog sizes of distinctive photo-identified individuals over multiple years (e.g. Carretta et al. 2016). However, these values are also difficult to apply to a single year, are sensitive to temporal variation in sampling, and underestimate $N_{\min }$ because they do not account for non-distinctive individuals.

Using the existing mark-recapture dataset to produce updated estimates of MHI false killer whale abundance would enhance the assessment and ensuing management of this population. However, the data are sparse, given the comparatively low sighting rates for this species (Baird et al. 2013b), and necessary sampling constraints impose possible spatiotemporal biases of unknown magnitude. In the present study, available mark-recapture methods were used to estimate the annual abundance of MHI false killer whales from 2000 to 2015 . The sensitivity of the re- 
sulting estimates to possible biases was explored by analyzing subsets of the data that were selected to minimize violations of mark-recapture assumptions. Until additional data and resources are available to explicitly quantify biases in the available data, the estimation framework herein can provide current abundance estimates to support management needs for this endangered population.

\section{MATERIALS AND METHODS}

\section{Data collection}

The Cascadia Research Collective (CRC) leads a research effort that has involved small-boat, multi- species surveys of odontocete cetaceans around the MHI every year since 2000. Details of the field operations are provided in Baird et al. (2013b), including the vessels used, survey design, and data collected. In brief, small-boat surveys were typically conducted for periods of 1 to $6 \mathrm{wk}$ off an island (or group of islands in close proximity) on 1 to 6 occasions each year (Table 1). These surveys were designed to maximize spatial coverage, and thus sightings of all possible odontocete species $(n=18)$, while minimizing overlap of survey tracklines during a given project period. However, the vessel was constrained to remain in areas with conditions suitable for detecting and working with multiple species, some with cryptic surfacing behavior, such that survey effort was primarily off the leeward sides of the islands unless sea

Table 1. Summary of Cascadia Research Collective odontocete survey effort off the main Hawaiian Islands (MHI) from 2000 to 2015 by year and island area, including the resulting number of MHI false killer whale (FKW) sightings. Maui Nui refers to the islands of Moloka'i, Lāna'i, Kaho'olawe, and Maui (from west to east). The primary harbors were Kekaha (A) on Kaua'i, Wai'anae (B) and Ko Olina (C) on O'ahu, Manele Bay (D) on Lāna'i, Lāhainā (E) on Maui, and Kawaihae (F) and Honokōhau (G) on Hawai'i Island, although a live-aboard vessel $(\mathrm{H})$ was used for some field projects

\begin{tabular}{|c|c|c|c|c|c|c|c|}
\hline Year & Island(s) & Month(s) & $\begin{array}{l}\text { Primary } \\
\text { harbor(s) }\end{array}$ & $\begin{array}{l}\text { On-effort } \\
\text { days }\end{array}$ & $\begin{array}{l}\text { On-effort } \\
\text { hours }\end{array}$ & $\begin{array}{c}\text { On-effort } \\
\text { distance }(\mathrm{km})\end{array}$ & $\begin{array}{l}\text { MHI FKW } \\
\text { sightings }\end{array}$ \\
\hline 2000 & Maui Nui & Feb-Apr, Nov-Dec & $\mathrm{E}$ & 44 & 312 & 3927 & 4 \\
\hline 2001 & Maui Nui & Jan-Mar & $\mathrm{E}$ & 28 & 203 & 2102 & 1 \\
\hline \multirow[t]{3}{*}{2002} & O’ahu & Apr-May & $\mathrm{B}$ & 9 & 59 & 888 & 1 \\
\hline & Maui Nui & Apr & $\mathrm{E}$ & 9 & 62 & 896 & 0 \\
\hline & Hawai'i & Apr, Sep-Oct & $\mathrm{G}$ & 31 & 234 & 2844 & 1 \\
\hline \multirow[t]{4}{*}{2003} & Kaua'i/Ni'ihau & May-Jun & $\mathrm{H}$ & 24 & 195 & 3222 & 0 \\
\hline & O’ahu & May & $\mathrm{H}$ & 13 & 111 & 1789 & 1 \\
\hline & Maui Nui & May & $\mathrm{H}$ & 16 & 106 & 1658 & 0 \\
\hline & Hawai'i & May, Oct & $\mathrm{G}, \mathrm{H}$ & 39 & 281 & 4287 & 0 \\
\hline 2004 & Hawai’i & Sep-Dec & G & 42 & 288 & 4656 & 5 \\
\hline \multirow[t]{2}{*}{2005} & Kaua'i/Ni'ihau & Oct-Nov & $\mathrm{A}$ & 24 & 146 & 2194 & 0 \\
\hline & Hawai'i & Jan-Feb & G & 17 & 124 & 2089 & 0 \\
\hline 2006 & Hawai'i & Mar-Apr, Jul, Nov-Dec & G & 73 & 515 & 8234 & 2 \\
\hline 2007 & Hawai'i & Aug & G & 17 & 130 & 2275 & 1 \\
\hline \multirow[t]{2}{*}{2008} & Kaua'i/Ni'ihau & Jun-Jul & $\mathrm{A}$ & 7 & 54 & 819 & 0 \\
\hline & Hawai'i & Apr-May, Jul, Dec & $\mathrm{G}$ & 65 & 500 & 8380 & 5 \\
\hline 2009 & Hawai'i & Apr-May, Oct, Dec & G & 46 & 331 & 5903 & 3 \\
\hline \multirow[t]{2}{*}{2010} & O’ahu & Oct & $\mathrm{C}$ & 14 & 105 & 1656 & 2 \\
\hline & Hawai'i & Apr, Jul-Aug, Dec & G & 58 & 415 & 7048 & 8 \\
\hline \multirow[t]{2}{*}{2011} & Kaua'i/Ni'ihau & Feb, Jul-Aug & $\mathrm{A}, \mathrm{H}$ & 23 & 153 & 2411 & 0 \\
\hline & Hawai'i & May, Aug-Sep, Oct-Nov & G & 63 & 466 & 7224 & 3 \\
\hline \multirow[t]{3}{*}{2012} & Kaua'i/Ni'ihau & Jan, Jun-Jul & $\mathrm{A}$ & 29 & 158 & 2763 & 0 \\
\hline & Maui Nui & Dec & $\mathrm{D}$ & 15 & 77 & 1415 & 0 \\
\hline & Hawai'i & May, Aug & $\mathrm{G}$ & 56 & 449 & 6886 & 0 \\
\hline \multirow[t]{2}{*}{2013} & Kaua'i/Ni'ihau & Feb, Jul-Aug & $\mathrm{A}$ & 15 & 93 & 1681 & 0 \\
\hline & Hawai'i & May, Oct-Nov & $\mathrm{G}$ & 34 & 286 & 4658 & 1 \\
\hline \multirow[t]{2}{*}{2014} & Kaua'i/Ni'ihau & Feb, Oct & $\mathrm{A}$ & 21 & 144 & 2860 & 1 \\
\hline & Hawai'i & Jul, Nov-Dec & $\mathrm{G}$ & 39 & 293 & 5516 & 0 \\
\hline \multirow[t]{3}{*}{2015} & Kaua'i/Ni‘ihau & Feb, Sep & $\mathrm{A}$ & 18 & 128 & 2336 & 0 \\
\hline & O`ahu & Jan-Feb & $\mathrm{C}$ & 4 & 30 & 565 & 0 \\
\hline & Hawai'i & Apr, May-Jun, Nov & $\mathrm{G}, \mathrm{F}$ & 34 & 262 & 5034 & 2 \\
\hline Total & & & & 927 & 6710 & 108216 & 41 \\
\hline
\end{tabular}


conditions were calm enough to survey elsewhere (Fig. 1). When odontocete groups were sighted, photographs were taken for species and individual identification. Individual identification of false killer whales is based primarily on nicks and notches in the trailing edge of the dorsal fin (Baird et al. 2008). During each false killer whale sighting, efforts were made to photograph the right or left side of the dorsal fin of all individuals present in the group, regardless of the distinctiveness (i.e. number or severity of nicks and notches) of the fin.

Other research groups and ocean users (e.g. whale watch operators, photographers) occasionally sight and take photo-identification images of MHI false killer whales. To enhance the amount of data available for studies of MHI false killer whales, CRC established an archive to which other groups and individuals can contribute their photographs and any associated information (e.g. date, location). These contributions range from data that were obtained in a manner largely consistent with that of CRC to images taken on an opportunistic basis. For the more opportunistic data, it is likely that not all individuals in the group were photographed and that individuals were not photographed at random with respect to the distinctiveness of their dorsal fins. While some contributors recorded a log of their survey effort, others did not. However, even if some measure of effort could be determined for each contributor and then related to their number of sightings, the resulting values would not be comparable to those from CRC given the various objectives and survey designs represented. The contributor archive includes a limited number of photographs taken earlier than 2000 (Baird et al. 2008), but only images overlapping with the years of the CRC surveys (i.e. 2000-2015; Table 2) were considered in the present study to ensure sufficient sample sizes for the abundance estimation.

\section{Photo processing}

Archived MHI false killer whale photographs taken during all sightings from 2000 to 2015 were sorted, scored, and compared following the process detailed in Baird et al. (2008). In summary, permanent and ephemeral markings on the dorsal fin and body were used to sort all within-sighting photographs by individual, regardless of the distinctiveness of the fin or quality of the image. For each sorted individual in a sighting, the best photograph taken was given 1 of 4 quality $(\mathrm{Q})$ ratings $(\mathrm{Q} 1=$ poor, $\mathrm{Q} 2=$ fair, Q3 = good, or Q4 = excellent), and the individual was assigned 1 of 4 distinctiveness (D) rankings (D1 = not distinctive, $\mathrm{D} 2=$ slightly distinctive, $\mathrm{D} 3=$ distinctive, and D4 = very distinctive) based on the prevalence of permanent markings on the dorsal fin. The best images of each individual, regardless of quality rating or distinctiveness ranking, were then compared with a catalog of previously sighted individuals for between-sighting matching, with all matches agreed on by at least 2 experienced matchers. To avoid biasing the mark-recapture estimates from possible false positive or false negative matches (Urian et al. 2015), the encounter histories of identi-

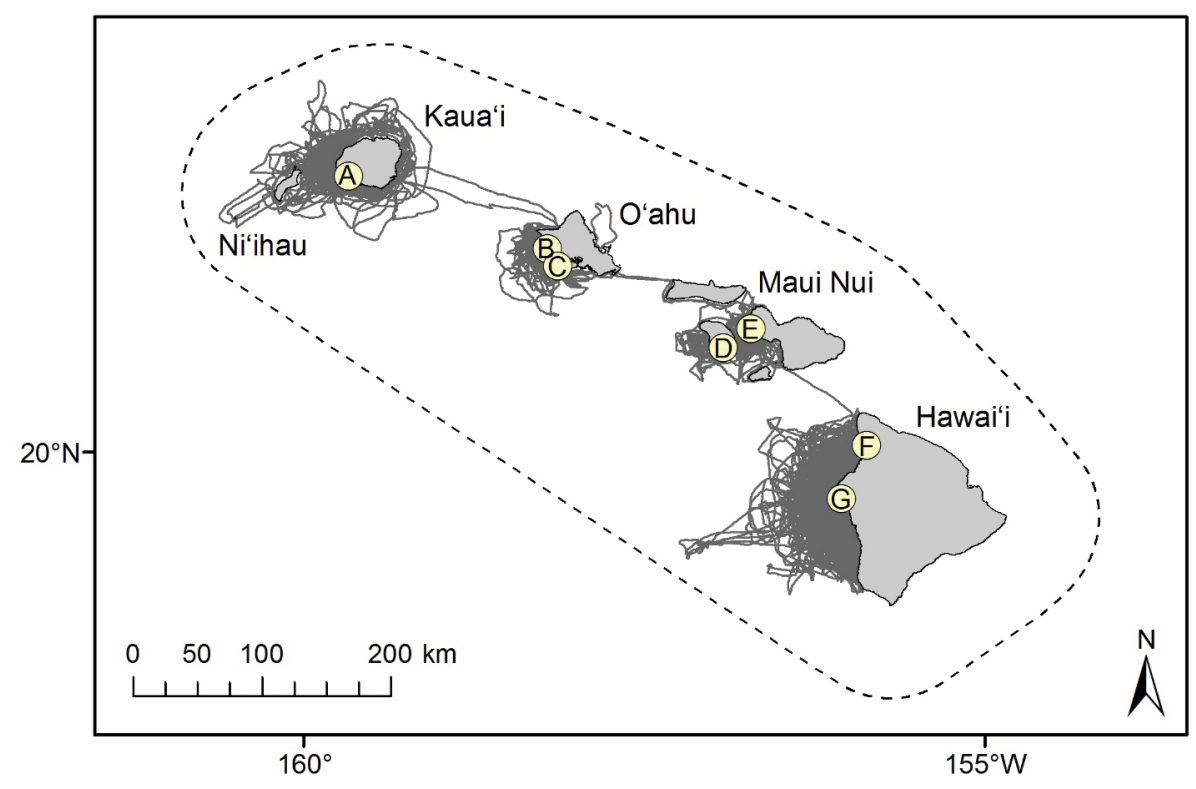

Fig. 1. The main Hawaiian Islands (MHI) with the Cascadia Research Collective survey effort (solid gray lines) and the current stock boundary for MHI false killer whales (dashed black line; Bradford et al. 2015). Maui Nui refers to the islands of Moloka'i, Lāna'i, Kaho'olawe, and Maui (from west to east). Circles with letters denote the primary harbors listed in Table 1 
Table 2. Summary of contributions to the archive of main Hawaiian Island (MHI) false killer whale (FKW) photo-identification (ID) data from 2000 to 2015. Main contributors are listed in order of the number of MHI FKW sightings that resulted in ID photos. Institutional contributors are Cascadia Research Collective (CRC) and the National Marine Fisheries Service Pacific Islands Fisheries Science Center (NMFS PIFSC). Individual contributors are listed by name. Note the number of photos include some duplicates between contributors reflecting a few cases when a sighting was shared by more than one contributor. Maui Nui refers to the islands of Moloka'i, Lāna'i, Kaho'olawe, and Maui (from west to east)

\begin{tabular}{|c|c|c|c|c|}
\hline Contributor & $\begin{array}{c}\text { MHI FKW } \\
\text { photo-ID } \\
\text { sightings }\end{array}$ & $\begin{array}{c}\text { ID } \\
\text { photos } \\
\text { contributed }\end{array}$ & Island(s) ID photos collected & Years ID photos collected \\
\hline $\mathrm{CRC}$ & 41 & 55734 & Kaua'i, O’ahu, Maui Nui, Hawai'i & 2000-2004, 2006-2011, 2013-2015 \\
\hline T. Cullins & 41 & 4854 & O’ahu & 2000, 2003, 2006-2015 \\
\hline D. McSweeney & 19 & 5797 & Hawai'i & 2005-2006, 2008, 2011-2015 \\
\hline D. Salden & 15 & 924 & Maui Nui & $2003-2004,2006,2009-2011$ \\
\hline D. Verbeck & 11 & 1197 & Hawai`i & $2010,2012-2015$ \\
\hline NMFS PIFSC & 10 & 5731 & O’ahu, Maui Nui, Hawai’i & $2005,2009,2013-2014$ \\
\hline C. Babbitt & 7 & 2251 & O’ahu & $2009,2012-2015$ \\
\hline M. Deakos & 7 & 1133 & Maui Nui & $2003,2005,2011$ \\
\hline All others ${ }^{\mathrm{a}}$ & 60 & 1810 & Kaua'i, O’ahu, Maui Nui, Hawai'i & $2001,2004-2008,2010-2015$ \\
\hline
\end{tabular}

fied individuals compiled for the present study only included D3 and D4 individuals represented by Q3 or Q4 photos. These individuals, hereafter characterized as 'distinctive', were assigned to 1 of 3 identified social clusters using the analysis of network modularity explained in Baird et al. $(2012,2015)$, which was rerun to include individuals identified through 2015.

\section{Abundance estimation}

Abundance can be estimated using either open or closed mark-recapture models, with either approach offering specific advantages (e.g. Schwarz \& Seber 1999, Pollock 2000). Closed population models are often preferred because they permit detailed modeling of capture probability, including the use of individual covariates, during periods when the population can be assumed to be demographically and geographically closed (e.g. White 2008). Open population models allow for births, deaths, immigration, and emigration between sampling periods, which makes them more suitable for longer studies (e.g. Nichols 2005). Methods that combine open and closed population models into a cohesive estimation framework, such as Pollock's robust design (Pollock 1982, Kendall et al. 1997), capitalize on the benefits of both approaches and are of increasing interest (e.g. Seber 2001).

The rarity of sighting MHI false killer whales and the level of survey effort in each year led to a limited number of individual recaptures within a year. Further, the within-year variation in effort made it infea- sible to identify 'closed' sampling periods that were consistent between years. Thus, closed mark-recapture models could not be used to estimate annual MHI false killer whale abundance from 2000 to 2015. Instead, abundance was estimated using an open model framework; specifically, the generalization of the classic Jolly-Seber model (Jolly 1965, Seber 1965) by Schwarz \& Arnason (1996) known as POPAN. POPAN parameterizes a super-population, which is the total number of individuals available for capture in the sampling area during the study period. This value does not extend to individuals that do not enter the sampling area and does not reflect losses over time. Thus, the super-population size may not represent a biological reality, but can be used to derive an estimate of abundance for each sampling period.

For the MHI false killer whale POPAN abundance estimation, years of the study (2000-2015) were considered the sampling periods, resulting in 16 yearly capture occasions. Encounter histories of distinctive individuals from the full contributor archive (Table 2) were compiled at an annual scale (i.e. individuals were recorded as encountered or not encountered by any contributor within each year). Models were fitted to the annual encounter histories using maximum likelihood estimation within the program MARK (White \& Burnham 1999), which was accessed through the package 'RMark' (Laake 2013) in the program R (R Core Team 2016). The estimated parameters in POPAN are apparent survival $(\phi)$, capture probability $(p)$, probability of entry into the population $(b)$, and super-population size $(N)$. To model these parameters, the logit link function was used for 
$\phi$ and $p$, the multinomial logit link function for $b$, and the log link function for $N$. The resulting parameter estimates were used to derive the main parameter of interest: $N_{i}$ which is the abundance of distinctive individuals at each capture occasion $i$, where $i=$ 2000, 2001, ..., 2015.

Given the longevity of false killer whales relative to the length of the study (Kasuya 1996), detectable changes in apparent survival (hereafter referred to as 'survival') were not expected. For that reason, and because abundance was the primary focus of the estimation, survival was assumed to be constant during the study period. However, the potential for survival to vary by social cluster was explored in a follow-up analysis (see 'Survival estimation' below). Eight models of capture probability were evaluated: $p(),. p(t)$, $p(T), p(s(T)), p(c), p(t+c), p(T+c)$, and $p(s(T)+C)$, where.$=$ constant,$t=$ time-varying by year, $T=$ linear trend over time, $s(T)=$ polynomial spline over time, $C=$ group-varying by cluster, and $+=$ additive model. The polynomial spline model was considered as a way to estimate time-varying capture probability with fewer parameters and was implemented using the $\mathrm{R}$ package 'splines'. Six degrees of freedom were specified in the spline model after determining iteratively that this value performed better than others in the model selection process (Altukhov et al. 2015). Cluster was used as a covariate to account for the potential effect of cluster-specific spatial use and behavior (Baird et al. 2012, 2015) on capture probability. Although differences in survey effort can help explain variation in capture probability in whale studies (e.g. Bradford et al. 2006), the lack of a consistent measure of effort across all data contributors precluded using effort as an additional covariate. Probability of entry was estimated as a function of yearly sampling period. Although this parameter likely also varies by cluster, the data were too sparse to support the increased complexity of an additive model. Finally, super-population size was modeled by cluster, allowing clusterspecific values of $N_{i}$ to be obtained.

With the 1 survival model, 8 capture probability models, 1 probability of entry model, and 1 superpopulation size model, a total of 8 models were fitted in the analysis. Model selection used Akaike's information criterion (Akaike 1973) corrected for small sample size $\left(\mathrm{AIC}_{\mathrm{c}}\right)$ (Hurvich \& Tsai 1989). The model with the lowest $\mathrm{AIC}_{\mathrm{C}}$ value was considered the best model, although the parameter estimates were averaged across all models proportionally to their Akaike weight to account for model uncertainty (Burnham \& Anderson 2002). Goodness-of-fit was assessed using the program RELEASE (Burnham et al. 1987), and lack of fit was accommodated through the use of a variance inflation factor $(\hat{c})$, which was determined by dividing the RELEASE chi-square test statistic by its degrees of freedom (Lebreton et al. 1992). A $\hat{c}>1$ is indicative of overdispersion in the data, which requires multiplying all variance estimates by $\hat{c}$ and computing quasi-AIC $\mathrm{C}_{\mathrm{C}}\left(\mathrm{QAIC}_{\mathrm{c}}\right)$ values for model selection (Anderson et al. 1994).

The modeling framework is associated with a number of assumptions: (1) the distinctive fin markings are unique and permanent and were correctly identified; (2) survival probabilities were homogeneous for all distinctive individuals, whether previously encountered (i.e. 'marked') or not; (3) capture probabilities were homogeneous for all distinctive individuals, whether previously encountered or not; (4) there was independence between distinctive individuals in terms of survival and capture; (5) sampling was instantaneous; and (6) the study area was constant (i.e. did not change). Violations to the first assumption are expected to be extremely low given the image quality and individual distinctiveness restrictions, the low rate of mark change estimated for these individuals (Baird et al. 2008), and the rigorous cataloging and match confirmation protocols. Differences in survival probabilities between previously encountered and 'new' distinctive individuals are unlikely, although there may be sources of heterogeneity that affect the survival of all distinctive individuals. However, because false killer whales are relatively longlived (Kasuya 1996), the influence of this variation was presumed to be minimal during the study. While capture probability was not expected to vary between marked and unmarked distinctive individuals, heterogeneity in capture probability as a function of other factors was anticipated. The various time- and group-varying capture probability models were incorporated to reduce this heterogeneity. Given that MHI false killer whales associate preferentially in social clusters (Baird et al. 2012), there is likely some dependence in the encounter data, but this overdispersion was mitigated with the $\hat{c}$ adjustment.

Avoiding violations to the fifth and sixth assumptions poses a greater challenge because of the nature of the sampling effort. For the primary data contributor $\mathrm{CRC}$, funding, research, and weather constraints collectively dictated the location, spatial extent, timing, and duration of each project (Table 1). The effort by other contributors also varied spatially and temporally, in addition to being more occasional or opportunistic in nature (Table 2). Establishing year as the capture occasion was a way to overcome this sampling variability in the estimation framework, but the resulting 
sampling scheme cannot be considered instantaneous (i.e. population additions and deletions could have occurred within capture occasions). Granted, the number of annual births and deaths in a small population of long-lived and slow-reproducing cetaceans is likely to be small. However, lengthy capture occasions can create individual heterogeneity in survival and, more importantly, lead to abundance estimates that cannot be clearly defined (Williams et al. 2002). This potential source of bias was one of several addressed through sensitivity analyses (see 'Sensitivity analyses' below). Finally, the concept of study area merits attention. This population of false killer whales uses the MHI exclusively, ranging throughout the islands (Fig. 1), although spatial use is not uniform and has been shown to vary by cluster (Baird et al. 2012). In this analysis, the full range of $\mathrm{MHI}$ false killer whales was considered the study area. Clearly, this area was not fully sampled each year, and the part of the study area that was sampled was not constant. This partial sampling would not be problematic if all distinctive individuals in the population used or passed through the sampled area at some point during the sampling period. Unfortunately, the validity of this assumption cannot be evaluated. Thus, $N_{i}$ is more appropriately characterized as the abundance of distinctive individuals using the sampled area each year, as opposed to the total annual abundance of distinctive individuals in the population.

\section{Sensitivity analyses}

Given the variability in the full MHI false killer whale mark-recapture dataset and the likelihood that at least some assumptions were violated, sensitivity analyses were conducted to evaluate how robust the $N_{i}$ estimates are to potential bias. Each analysis entailed estimating abundance from a data subset specified to reduce some form of bias. The POPAN estimation framework was applied using the parameter models and process described above unless otherwise noted. First, to account for some of the sampling variation and possible bias introduced by the occasional and opportunistic data contributions, the abundance of distinctive MHI false killer whales was estimated using only data contributed by CRC. Second, because encounter data from nonCRC contributors increased over the study period (Table 2), abundance was estimated using only data collected (by all contributors) from 2008 to 2015. Bias was expected to be reduced because data inputs were more consistent during these years, and the number of distinctive individuals identified was at a maximum (Fig. 2A). With the decreased number of years in this study period, only 3 degrees of freedom were specified in the polynomial spline models of capture probability. Third, to minimize violations of the instantaneous sampling assumption, abundance
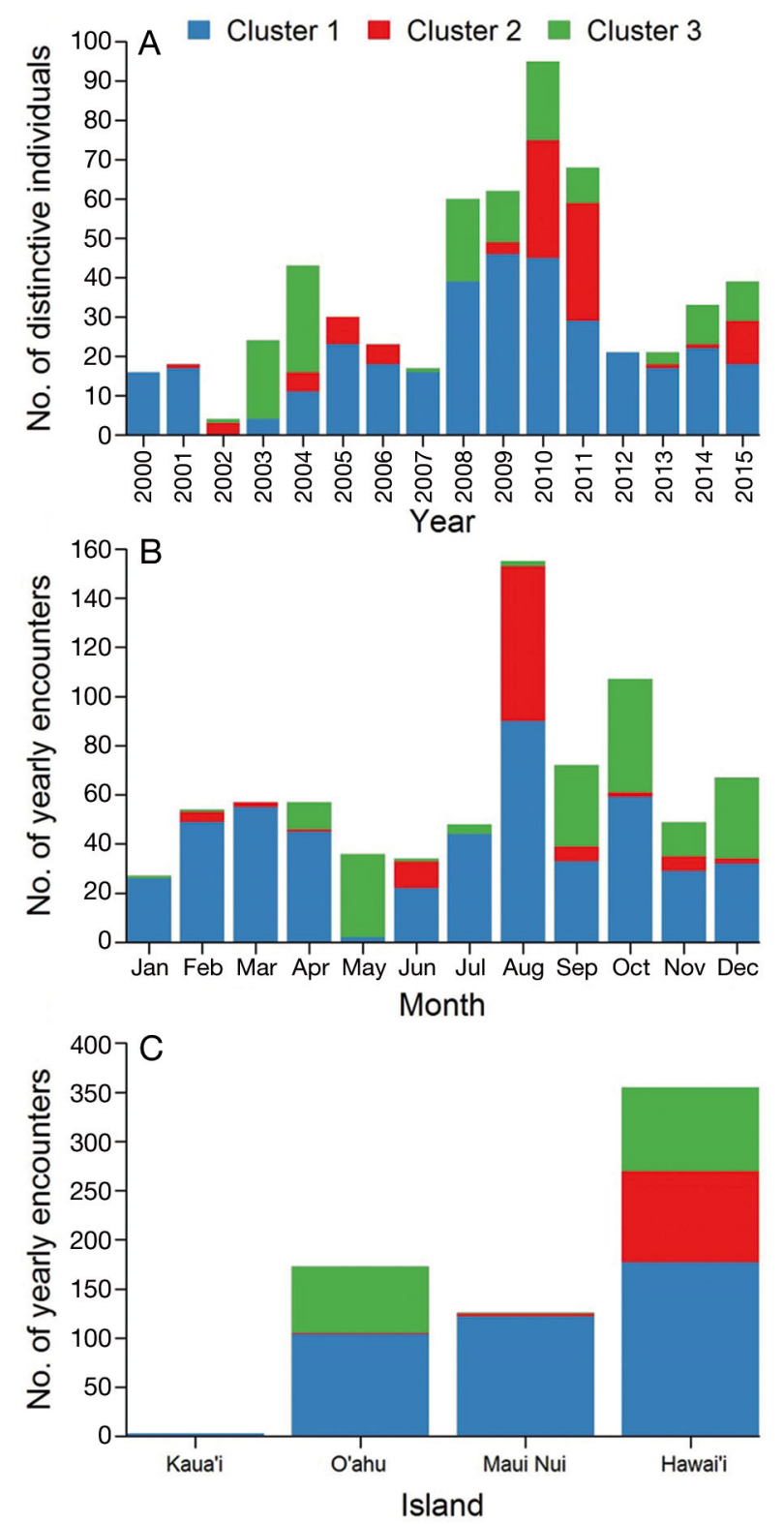

Fig. 2. Encounter histories of distinctive main Hawaiian Island false killer whales $(\mathrm{n}=171)$ encountered by all contributors to the photo-identification data archive from 2000 to 2015. (A) Yearly encounters of distinctive individuals ( $\mathrm{n}=$ 574) used in the mark-recapture abundance estimation. (B) Yearly encounters of distinctive individuals by month $(\mathrm{n}=$ 763). (C) Yearly encounters of distinctive individuals by island area $(\mathrm{n}=657)$. Encounter histories are shown by social cluster. Maui Nui refers to the islands of Moloka'i, Lāna'i, Kaho'olawe, and Maui (from west to east) 
was estimated using only data collected (by all contributors) from July to December. A 6 mo period was chosen to ensure there were enough data to perform the estimation, and the second half of the year was selected because more distinctive individuals were seen in this period than from January to June (Fig. 2B). Fourth, to decrease the effect of the spatial variability in sampling, abundance was estimated using only data collected (by all contributors) from Hawai'i Island, the island with the most yearly encounters of distinctive individuals (Fig. 2C). Since there was no effort from Hawai'i Island until 2002 and only 3 distinctive individuals were identified up to 2003, the first year of this estimation was 2004. The polynomial spline models of capture probability were based on 5 degrees of freedom given the shortening of this study period.

\section{Survival estimation}

Although the primary objective of the present study is abundance estimation, the open population dataset and analytical framework allowed for a follow-up evaluation of survival probabilities. In particular, the potential for survival to vary by social cluster was examined given that the 3 clusters have been shown to use the study area differently (Baird et al. 2012) and to interact with nearshore fisheries to potentially varying degrees (Baird et al. 2015). A separate analysis was performed to target the estimation of survival and reduce the number of estimated parameters. Specifically, the Cormack-Jolly-Seber (CJS) model (Cormack 1964, Jolly 1965, Seber 1965) was used to estimate survival of MHI false killer whales from 2000 to 2015. Almost all components of the POPAN analysis were replicated in the CJS survival estimation, including the dataset and scale, the numerical methods and software, the models of capture probability, and the approaches to model selection, model averaging, and goodness-of-fit. The only difference was that in addition to the $\phi($.) (i.e. constant survival) model used in the POPAN assessment, a $\phi(c)$ model was also evaluated, where $c=$ groupvarying by cluster. With the 2 survival models and 8 models of capture probability, a total of 16 models were fitted in the analysis. The previously stated assumptions apply, although without the requirements for newly encountered distinctive individuals that were not previously 'marked', as the CJS model conditions on the first capture and the estimates pertain only to those marked individuals (e.g. Pollock \& Alpizar-Jara 2005).

\section{Proportion distinctive}

As $N_{i}$ only reflects the annual number of distinctive MHI false killer whales associated with the sampled area, an adjustment was needed to account for the number of non-distinctive individuals also using the sampled area in each year. Following Wilson et al. (1999), the proportion of distinctive individuals $(\theta)$ encountered was estimated, although group served as the analytical unit instead of survey day. That is, for each group sighted by CRC, all high-quality (Q3 or Q4) photos were used to determine the numbers of non-distinctive (D1 and D2) and distinctive (D3 and D4) individuals. Secondary and ephemeral identification features such as scars, scratches, and skin coloration were used to differentiate non-distinctive individuals within a group. Instead of summing the numbers of distinctive and non-distinctive individuals over all groups and then using the summed values to compute $\theta$ (Wilson et al. 1999), $\theta$ was calculated as the mean proportion of distinctive individuals across all groups so that the variance in $\theta$ reflects heterogeneity in the sampling process. To avoid proportions biased by small group sizes, only groups with at least 4 individuals were used to estimate $\theta$. Using $\theta$ as an abundance scalar assumes that there is at least 1 high-quality photograph of all non-distinctive and distinctive individuals in each group or, in cases when high-quality images of all individuals were not obtained, that the individuals with highquality photographs are a representative sample of the proportion marked. With the consistent emphasis on photographing all individuals in a group regardless of their distinctiveness, only CRC sightings were used to determine $\theta$.

If MHI false killer whale sighting rates had been higher, the increased number of sightings could have been used to produce estimates of $\theta$ that vary by year (e.g. Wilson et al. 1999) or by other potentially important attributes (e.g. social cluster). Instead, given the limited number of CRC sightings between 2000 and 2015 ( $\mathrm{n}=41$; Tables $1 \& 2$ ), only 1 estimate of $\theta$ was determined and applied to the abundance estimation. However, an analysis was conducted to evaluate the effect of relevant factors on the proportion of distinctive individuals in each group and to ensure that significant sources of variation or bias were not overlooked in the current sample of sightings. Specifically, linear models were used to assess whether the proportion of distinctive individuals in each group varied as a function of the continuous variables Year (yearly sampling period 2000-2015), Duration (sighting duration in decimal hours), Frames (number of 
unprocessed photographs taken during each sighting), and Group size (number of individuals present in each sighting), as well as the categorical variable Cluster (social cluster 1, 2, or 3). Year was tested to examine whether the proportion of distinctive individuals had increased or decreased over the study period, whether due to ecological factors or efficiencies in data collection. Duration, Frames, and Group size were included to determine whether the proportion of distinctive individuals changed when sightings were longer, more photographs were taken, or more individuals were present, respectively, which would suggest a bias related to data collection. Finally, Cluster was tested to account for ecological differences in the proportion of distinctive individuals by social unit; for example, due to possible differences in rates of interaction with and dorsal fin injuries from nearshore fisheries (Baird et al. 2015). The covariate models were evaluated using a backward stepwise procedure and selected using $\mathrm{AIC}_{\mathrm{c}}$. The proportion distinctive analysis was implemented in program R (R Core Team 2016).

Total annual abundance in the sampled area was estimated as:

$$
N_{\text {total }, i}=\frac{N_{i}}{\theta}
$$

where $N_{\text {total }, i}$ is abundance of all individuals (distinctive and non-distinctive) associated with the sampled area at each capture occasion $i$, where $i=2000,2001$, $\ldots, 2015 ; N_{i}$ is the model-averaged estimate of distinctive individual abundance at each capture occasion $i$ resulting from the full POPAN analysis; and $\theta$ is the proportion of distinctive individuals informed by the linear modeling analysis. As $N_{i}$ and $\theta$ are independent estimates, the variance (var) of $N_{\text {total, } i}$ was estimated using the delta method (Seber 1982) as follows:

$$
\operatorname{var}\left(N_{\text {total }, i}\right)=N_{\text {total }, i}^{2}\left(\frac{\operatorname{var}\left(N_{i}\right)}{N_{i}^{2}}+\frac{\operatorname{var}(\theta)}{\theta^{2}}\right)
$$

Log-normal 95\% CIs (Burnham et al. 1987) for $N_{\text {total }, i}$ were then computed.

\section{RESULTS}

\section{Photo-identification data}

CRC conducted surveys for odontocetes throughout the MHI on 927 d between February 2000 and November 2015 (Table 1, Fig. 1), which led to 41 sightings with MHI false killer whale groups on 40
$(4.3 \%)$ of the survey days. Accounting for all photoidentification contributors ( $\mathrm{n}=54$; Table 2 ), including CRC, 211 groups of MHI false killer whales were sighted on $182 \mathrm{~d}$ between March 2000 and December 2015. While CRC contributed the most sightings and identification photographs to the data archive, the non-CRC contributions not only enhanced the spatial and seasonal coverage of sightings, but also provided information from 2 years (i.e. 2005 and 2012) in which CRC did not sight MHI false killer whales (Table 2).

Focusing on the encounter histories of distinctive individuals represented by high-quality photos, there are a total of 858 encounters of 171 distinctive individuals in the full contributor dataset, with 580 $(67.6 \%)$ of the individual encounters from cluster 1 , $97(11.3 \%)$ from cluster 2 , and $181(21.1 \%)$ from cluster 3. Of the encounters from all contributors, 451 $(52.6 \%)$ of $143(83.6 \%)$ individuals are from CRC, with $244(54.1 \%)$ of the CRC individual encounters from cluster 1, 85 (18.8\%) from cluster 2, and 122 $(27.1 \%)$ from cluster 3 . Of the 171 individuals encountered by all contributors, 81 (47.4\%) were assigned to cluster 1, $44(25.7 \%)$ to cluster 2, and 46 $(26.9 \%)$ to cluster 3 . For the 143 individuals encountered by CRC, $60(42.0 \%)$ were assigned to cluster 1 , $43(30.1 \%)$ to cluster 2 , and $40(28.0 \%)$ to cluster 3. After compiling the encounter histories at an annual scale for the abundance estimation, the full dataset contains 574 yearly encounters of distinctive individuals, with $342(59.6 \%)$ of the encounters from cluster 1, $97(16.9 \%)$ from cluster 2, and $135(23.5 \%)$ from cluster 3 . Of the yearly encounters from all contributors, $339(59.1 \%)$ are from CRC, with $161(47.5 \%)$ of the CRC yearly encounters from cluster 1, 85 (25.1\%) from cluster 2, and $93(27.4 \%)$ from cluster 3.

Summarizing the annual, monthly, and spatial patterns of the full photo-identification dataset (Fig. 2), distinctive MHI false killer whales were encountered in each year of the study period, although there is variation in the number of yearly encounters, with relatively more distinctive individuals encountered in the years 2008-2011 (Fig. 2A). Compiling the 858 distinctive individual encounters into yearly encounters by month (i.e. individuals were recorded as encountered or not encountered by any contributor within each month of each year), the 763 yearly encounters by month reveal that, collectively, distinctive individuals were encountered in each month over the course of the study period (although never within a given year), with most (59.0\%) of the yearly encounters by month occurring between August and December (Fig. 2B). Collapsing the 858 distinctive in- 
dividual encounters into yearly encounters by island (i.e. individuals were recorded as encountered or not encountered by any contributor off each island area within each year), the 657 yearly encounters by island indicate that although MHI false killer whales were encountered throughout the archipelago, most $(54.0 \%)$ of the yearly encounters by island were off the island of Hawai'i (Fig. 2C).

In terms of the 171 distinctive individuals photoidentified (Fig. 3), individual whales were encountered in as many as 11 of the $16 \mathrm{yr}$, although most individuals $(53.8 \%)$ were encountered in only 1 or $2 \mathrm{yr}$ (median $=2 \mathrm{yr}$; Fig. 3A). Although relatively
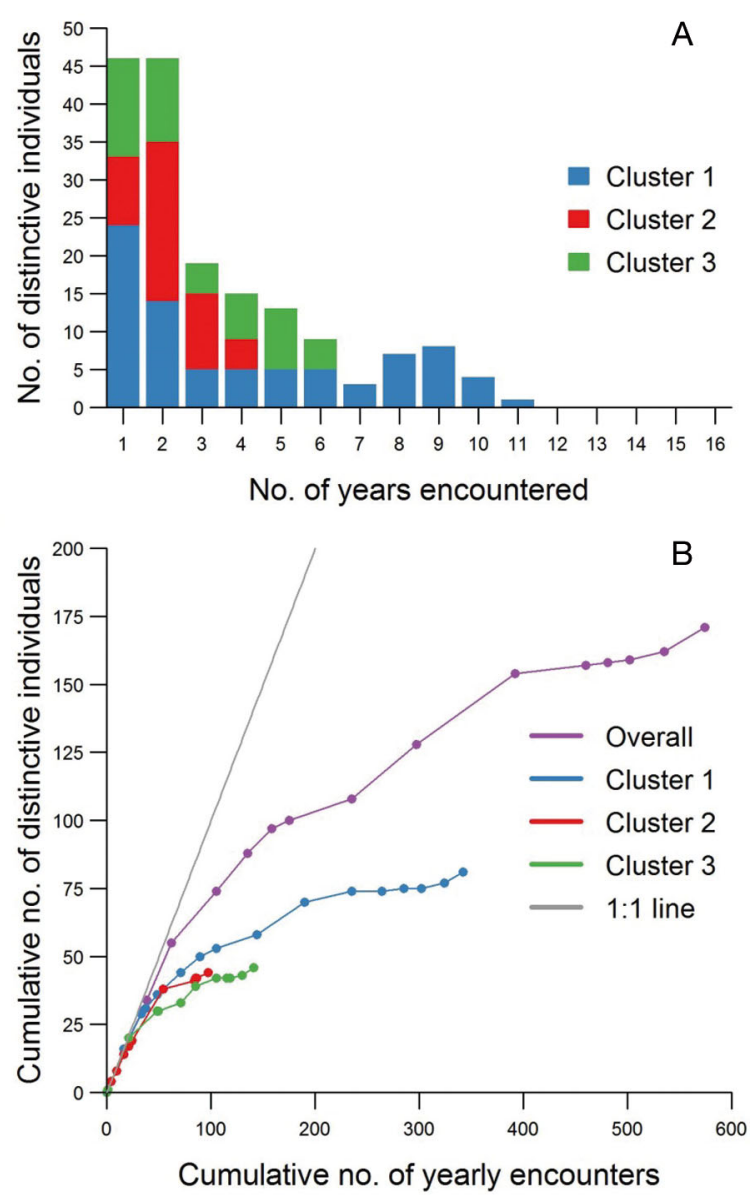

Fig. 3. Summaries of distinctive main Hawaiian Island false killer whales $(n=171)$ encountered by all contributors to the photo-identification data archive from 2000 to 2015. (A) Frequency of yearly encounters of distinctive individuals. (B) Rate of discovery of these individuals (overall and by social cluster). The discovery curve relates the cumulative number of yearly encounters $(n=574)$ to the cumulative number of distinctive individuals $(\mathrm{n}=171)$, with the $1: 1$ line representing the trajectory that would occur if all individuals encountered were previously unidentified. The points on each line represent years of the study period fewer individuals were encountered in 3 or more years, the numbers of previously unidentified individuals encountered each year began to level off in the last 6 yr of the study period, particularly for cluster 1 individuals (Fig. 3B). The annual, monthly, and spatial patterns of distinctive individual encounters in the CRC dataset are shown in Fig. S1 in the Supplement at www.int-res.com/articles/suppl/n036p297_ supp.pdf, and the yearly encounters of the 143 distinctive individuals photo-identified by CRC are summarized in Fig. S2 in the Supplement.

\section{Abundance of distinctive individuals}

Goodness-of-fit testing in the program RELEASE revealed that there is overdispersion in the annual encounter histories of MHI false killer whales established from the full contributor archive. Specifically, the chisquare test statistic $\left(\chi^{2}=94.73\right)$ divided by its degrees of freedom $(\mathrm{df}=64)$ resulted in a $\hat{c}$ of 1.48 . Of the 8 fitted models, the one allowing capture probability to vary by time and cluster received virtually all of the QAIC $_{\mathrm{C}}$ weight (Table 3). Annual capture probabilities are highest in each year for cluster 1 and lowest for cluster 2, with the yearly model-averaged estimates ( $\mathrm{n}=16$ ) averaging 0.418 (range $=0.056-0.876$ ) for cluster 1, 0.157 (range $=0.011-0.575$ ) for cluster 2 , and 0.272 (range $=0.026-0.758$ ) for cluster 3 (Table S1 in the Supplement). Model-averaged estimates indicate that the annual abundance of distinctive individuals using the sampled area was highest in cluster 1 and lowest in cluster 3, although the $95 \%$ CIs overlap for all cluster estimates in most years (Table 4). However, the cluster 1 estimates are likely significantly higher than those for cluster 3 in 2006 and 2009-2011 given the non-overlapping $95 \%$ CIs in those years. Point estimates of the total number of distinctive individuals associated with the sampled area show some variation from year to year, potentially influenced by annual variation in survey effort (Tables 1 \& 2), although the $95 \%$ CIs overlap in all cases (Table 4 ). Overall, the estimates of distinctive individuals using the sampled area each year are relatively low, with $N_{2015}$ estimated as 119 individuals ( $\mathrm{SE}=16 ; 95 \% \mathrm{CI}=88-151)$.

The sensitivity analyses using data subsets did not result in major departures from the abundance estimation based on the full MHI false killer whale dataset (Fig. 4, Table S1 in the Supplement). The $N_{i}$ estimates from the analysis using only CRC data are similar to those from the full estimation, although the estimates from the first $2 \mathrm{yr}$ of the study period are markedly less precise (Fig. 4A). Estimates of annual distinctive indi- 
Table 3. Model selection results from the POPAN mark-recapture estimation of distinctive main Hawaiian Island false killer whale abundance from 2000 to 2015. The notation of the models $(n=8)$ and parameters $(n=4)$ is explained in 'Materials and methods: Abundance estimation'. $\mathrm{QAIC}_{\mathrm{c}}$ is the quasi-Akaike's information criterion corrected for small sample size; $\Delta \mathrm{QAIC}_{\mathrm{c}}$ is the difference in the QAIC $_{C}$ of a given model from the QAIC $_{C}$ of the best model; QAIC $_{C}$ weight is the quasi-Akaike weight used for model averaging

\begin{tabular}{|lrrrc|}
\hline Model & QAIC $_{\mathrm{c}}$ & $\Delta$ QAIC $_{\mathrm{c}}$ & $\begin{array}{r}\text { QAIC }_{\mathrm{c}} \\
\text { weight }\end{array}$ & $\begin{array}{c}\text { No. } \\
\text { parameters }\end{array}$ \\
\hline$\phi() p.(t+c) b(t) N(c)$ & 1221.31 & 0.00 & $>0.999$ & 37 \\
$\phi() p.(t) b(t) N(c)$ & 1268.62 & 47.31 & $<0.001$ & 35 \\
$\phi() p.(s(T)+\mathrm{c}) b(t) N(c)$ & 1275.29 & 53.98 & $<0.001$ & 28 \\
$\phi() p.(s(T)) b(t) N(c)$ & 1312.84 & 91.53 & 0.000 & 26 \\
$\phi() p.(T+c) b(t) N(c)$ & 1340.27 & 118.96 & 0.000 & 23 \\
$\phi() p.(c) b(t) N(c)$ & 1350.34 & 129.03 & 0.000 & 22 \\
$\phi() p.(T) b(t) N(c)$ & 1371.46 & 150.15 & 0.000 & 21 \\
$\phi() p.() b.(t) N(c)$ & 1374.09 & 152.78 & 0.000 & 20 \\
\hline
\end{tabular}

Table 4. Model-averaged mark-recapture estimates of distinctive main Hawaiian Island false killer whale abundance $\left(N_{i}\right)$ associated with the sampled area from 2000 to 2015, shown by each social cluster and in total. The SE and $95 \%$ CI follow each estimate in parentheses. The sum of the clusterspecific $N_{i}$ values differs from the total $N_{i}$ presented by one individual in some cases due to rounding error

\begin{tabular}{|ccccc|}
\hline Year & $\begin{array}{c}\text { Cluster } 1 N_{i} \\
(\mathrm{SE} ; 95 \% \mathrm{CI})\end{array}$ & $\begin{array}{c}\text { Cluster } 2 N_{i} \\
(\mathrm{SE} ; 95 \% \mathrm{CI})\end{array}$ & $\begin{array}{c}\text { Cluster } 3 N_{i} \\
(\mathrm{SE} ; 95 \% \mathrm{CI})\end{array}$ & $\begin{array}{c}\text { Total } N_{i} \\
(\mathrm{SE} ; 95 \% \mathrm{CI})\end{array}$ \\
\hline 2000 & $56(8 ; 40-73)$ & $41(8 ; 25-57)$ & $36(6 ; 24-47)$ & $132(20 ; 92-172)$ \\
2001 & $53(8 ; 37-68)$ & $38(8 ; 23-53)$ & $33(6 ; 23-44)$ & $124(19 ; 88-161)$ \\
2002 & $50(7 ; 35-64)$ & $36(7 ; 22-50)$ & $31(5 ; 21-42)$ & $117(17 ; 83-151)$ \\
2003 & $47(7 ; 33-60)$ & $34(7 ; 21-46)$ & $29(5 ; 20-39)$ & $110(16 ; 78-142)$ \\
2004 & $44(7 ; 31-57)$ & $32(6 ; 20-44)$ & $28(5 ; 19-37)$ & $103(15 ; 73-133)$ \\
2005 & $52(9 ; 35-70)$ & $38(8 ; 23-53)$ & $33(6 ; 21-45)$ & $124(21 ; 83-165)$ \\
2006 & $51(5 ; 41-61)$ & $37(6 ; 26-48)$ & $32(4 ; 24-40)$ & $120(12 ; 97-143)$ \\
2007 & $48(5 ; 38-58)$ & $35(5 ; 24-45)$ & $30(4 ; 23-38)$ & $112(11 ; 90-135)$ \\
2008 & $45(5 ; 35-55)$ & $32(5 ; 23-42)$ & $28(4 ; 21-36)$ & $106(11 ; 84-128)$ \\
2009 & $57(5 ; 47-66)$ & $41(5 ; 31-51)$ & $36(4 ; 28-44)$ & $134(9 ; 116-153)$ \\
2010 & $53(5 ; 44-63)$ & $39(5 ; 29-48)$ & $34(4 ; 26-41)$ & $126(10 ; 107-145)$ \\
2011 & $50(5 ; 40-60)$ & $36(5 ; 27-46)$ & $32(4 ; 24-39)$ & $118(10 ; 98-138)$ \\
2012 & $48(5 ; 38-59)$ & $35(5 ; 25-45)$ & $31(4 ; 23-38)$ & $114(11 ; 92-136)$ \\
2013 & $46(6 ; 35-56)$ & $33(5 ; 24-42)$ & $29(4 ; 21-36)$ & $107(12 ; 85-130)$ \\
2014 & $46(6 ; 34-58)$ & $33(5 ; 23-43)$ & $29(4 ; 21-37)$ & $108(13 ; 82-134)$ \\
2015 & $51(7 ; 37-65)$ & $37(6 ; 24-49)$ & $32(5 ; 22-42)$ & $119(16 ; 88-151)$ \\
\hline
\end{tabular}

vidual abundance derived from the temporally truncated dataset (2008-2015) are also similar to those from the full analysis, although the 2008 estimate is substantially less precise and the 2014-2015 point estimates are somewhat lower (Fig. 4B). The analysis based on data collected only during July to December produced estimates of $N_{i}$ that are similar in magnitude and precision to those from the full estimation (Fig. 4 C). Finally, the $N_{i}$ estimates from the Hawai'i Island dataset are similar to those from the full analysis, although the 2004 estimate is likely significantly lower (based on the non-overlapping 95\% CIs) and the
2012-2015 point estimates are notably higher (Fig. 4D). The CRC, 2008-2015, and Hawai'i Island data subsets were found to be overdispersed, and ${ }_{\mathrm{c}}$ values of $1.15,2.19$, and 1.78 were applied in each estimation, respectively. The best model for the CRC, 2008-2015, JulyDecember, and Hawai'i Island analyses contained $p(t)\left(\mathrm{QAIC}_{\mathrm{c}}\right.$ weight $=$ 0.602; no. parameters $=35), p(t+c)$ $\left(\right.$ QAIC $_{\mathrm{c}}$ weight $>0.999$; no. parameters $=21), p(t+c)\left(\mathrm{AIC}_{\mathrm{c}}\right.$ weight $=1.000$; no. parameters $=37)$, and $p(t+c)$ $\left(\right.$ QAIC $_{\mathrm{c}}$ weight $>0.999$; no. parameters $=29$ ), respectively (Table $\mathrm{S} 2$ in the Supplement).

\section{Cluster-specific survival}

Although the POPAN abundance estimation resulted in an estimate of MHI false killer whale survival during the study period $(\phi=0.939, \mathrm{SE}=0.012$, $95 \% \mathrm{CI}=0.911-0.959)$, the CJS survival estimation evaluated the potential for survival to vary by social cluster. The same overdispersed encounter histories from the full contributor archive were used, and thus a $\hat{c}$ of 1.48 was applied to account for lack of fit. Of the 16 models tested, 2 received all of the quasi-Akaike weight: (1) $\phi($. $p(t+c)$ with QAIC $_{c}$ weight $=0.761$ and no. parameters $=18$, and (2) $\phi(\mathrm{c}) p(t+c)$ with QAIC $_{c}$ weight $=0.239$ and no. parameters $=20$ (Table S2 in the Supplement). The cluster-varying survival model was only 2.322 QAIC $_{c}$ units from the constant survival model, indicating that either model is plausible given the available data (Burnham \& Anderson 2002). Model-averaged survival estimates for clusters 1, 2, and 3 are $0.943(\mathrm{SE}=0.013,95 \% \mathrm{CI}=0.911-0.964)$, $0.954(\mathrm{SE}=0.023,95 \% \mathrm{CI}=0.881-0.983)$, and 0.944 $(\mathrm{SE}=0.016,95 \% \mathrm{CI}=0.903-0.968)$, respectively (Table S1 in the Supplement).

\section{Proportion distinctive and total abundance}

In the analysis of factors affecting the proportion of distinctive MHI false killer whales in each CRC 

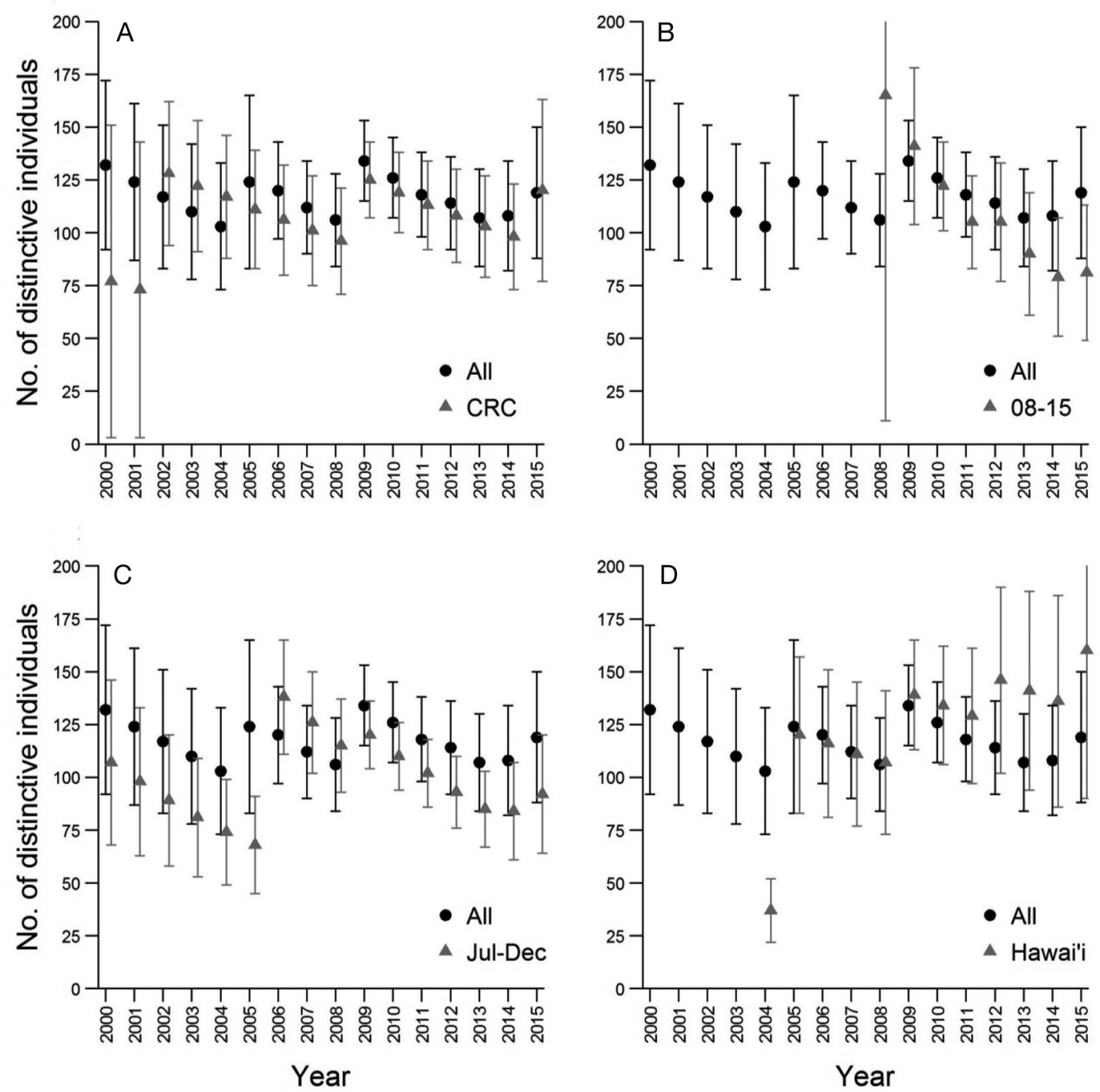

Fig. 4. Comparisons of the annual estimates of distinctive individual abundance $\left(N_{i}\right)$ using the sampled area from the markrecapture analysis of the full main Hawaiian Island false killer whale dataset ('All') to $N_{i}$ estimates from sensitivity analyses using various data subsets. (A) Data collected by only Cascadia Research Collective (CRC). (B) Data from only the years 2008 to 2015. (C) Data from only the months of July to December. (D) Data obtained only from Hawai'i Island. Estimates of $N_{i}$ at each year are systematically jittered for clarity; error bars represent $95 \%$ CIs, with some upper CIs truncated

group, none of the covariate coefficients in the full model were significant (i.e. with a $t$-statistic p-value $<0.05$; Table S3 in the Supplement), and the backward stepwise procedure selected the null model (Table 5), indicating that a relationship between the proportion of distinctive individuals and the covariates Year, Duration, Frames, Group size, and Cluster could not be discerned given the available data. The lack of significant association or bias in the proportion of distinctive individuals justified the use of the single $\theta$ estimate, which was calculated as 0.715 ( $\mathrm{SE}=0.018$ ) from the $35 \mathrm{CRC}$ sightings between 2000 and 2015 that contained at least 4 individuals. The estimate of $\theta$ was applied to the estimates of $N_{i}$ from the full POPAN abundance estimation, resulting in a time series of the yearly abundance of all individuals (distinctive and non-distinctive) associated with the sampled area (Table 6). In general, the $N_{\text {total, } i}$ estimates suggest that fewer than 200 individuals were present in the sampled area in each year, with $N_{\text {total, } 2015}$ estimated as 167 individuals ( $\mathrm{SE}=23 ; 95 \%$ $\mathrm{CI}=128-218)$.

\section{DISCUSSION}

The POPAN estimation framework implemented in the present study resulted in mark-recapture esti- 
Table 5. Model selection results from the backward stepwise procedure used to evaluate the effect of the covariates Year, Duration, Frames, Group size, and Cluster on the proportion of distinctive individuals in sightings of main Hawaiian Island false killer whale groups. $\mathrm{AIC}_{\mathrm{c}}$ is the Akaike's information criterion corrected for small sample size. The selected model is shown in bold

\begin{tabular}{|lccc|}
\hline Model covariates & $\begin{array}{c}\text { Residual } \\
\text { df }\end{array}$ & $\begin{array}{c}\text { Log- } \\
\text { likelihood }\end{array}$ & AIC $_{c}$ \\
\hline Year + Duration + Frames + Group size + Cluster & 28 & 31.177 & -40.815 \\
Year + Duration + Frames + Group size & 30 & 30.575 & -46.150 \\
Duration + Frames + Group size & 31 & 30.548 & -49.028 \\
Frames + Group size & 32 & 30.486 & -52.085 \\
Frames & 33 & 30.042 & -53.310 \\
Null & $\mathbf{3 4}$ & $\mathbf{2 9 . 3 8 7}$ & $\mathbf{- 5 4 . 3 9 9}$ \\
\hline
\end{tabular}

Table 6. Mark-recapture estimates of distinctive and non-distinctive main Hawaiian Island false killer whales $\left(N_{\text {total }, i}\right)$ associated with the sampled area from 2000 to 2015, shown by each social cluster and in total. The SE and $95 \%$ CI follow each estimate in parentheses. The sum of the cluster-specific $N_{\text {total }, i}$ values differs from the total $N_{\text {total }, i}$ presented by one individual in some cases due to rounding error

\begin{tabular}{|ccccc|}
\hline Year & $\begin{array}{c}\text { Cluster } 1 N_{\text {total }, i} \\
(\mathrm{SE} ; 95 \% \mathrm{CI})\end{array}$ & $\begin{array}{c}\text { Cluster } 2 N_{\text {total }, i} \\
(\mathrm{SE} ; 95 \% \mathrm{CI})\end{array}$ & $\begin{array}{c}\text { Cluster } 3 N_{\text {total }, i} \\
(\mathrm{SE} ; 95 \% \mathrm{CI})\end{array}$ & $\begin{array}{c}\text { Total } N_{\text {total }, i} \\
\left(\mathrm{SE}_{\mathbf{2}} 95 \% \mathrm{CI}\right)\end{array}$ \\
\hline 2000 & $79(12 ; 58-106)$ & $57(12 ; 38-84)$ & $50(9 ; 36-69)$ & $185(29 ; 137-251)$ \\
2001 & $74(11 ; 55-99)$ & $53(11 ; 36-79)$ & $47(8 ; 34-65)$ & $174(27 ; 129-234)$ \\
2002 & $69(10 ; 52-93)$ & $50(10 ; 34-74)$ & $44(7 ; 32-61)$ & $163(25 ; 122-219)$ \\
2003 & $65(10 ; 49-87)$ & $47(9 ; 32-69)$ & $41(7 ; 30-57)$ & $154(23 ; 115-206)$ \\
2004 & $61(9 ; 46-82)$ & $44(9 ; 30-65)$ & $39(6 ; 28-53)$ & $144(22 ; 108-193)$ \\
2005 & $73(13 ; 52-103)$ & $53(11 ; 36-79)$ & $46(9 ; 32-67)$ & $173(30 ; 124-241)$ \\
2006 & $71(7 ; 58-87)$ & $51(8 ; 38-69)$ & $45(6 ; 35-58)$ & $167(17 ; 137-204)$ \\
2007 & $67(7 ; 54-83)$ & $48(7 ; 36-65)$ & $42(6 ; 33-54)$ & $157(16 ; 128-193)$ \\
2008 & $63(7 ; 50-79)$ & $45(7 ; 33-61)$ & $40(5 ; 31-52)$ & $148(16 ; 119-183)$ \\
2009 & $80(7 ; 67-95)$ & $58(7 ; 45-74)$ & $50(6 ; 41-62)$ & $187(14 ; 162-217)$ \\
2010 & $75(7 ; 62-90)$ & $54(7 ; 42-70)$ & $47(5 ; 38-59)$ & $176(14 ; 150-207)$ \\
2011 & $70(7 ; 57-86)$ & $51(7 ; 39-66)$ & $44(5 ; 35-56)$ & $165(15 ; 139-197)$ \\
2012 & $68(8 ; 54-85)$ & $49(7 ; 37-65)$ & $43(6 ; 33-55)$ & $160(16 ; 131-195)$ \\
2013 & $64(8 ; 50-81)$ & $46(7 ; 35-61)$ & $40(6 ; 31-53)$ & $150(17 ; 121-186)$ \\
2014 & $64(9 ; 49-84)$ & $46(7 ; 34-63)$ & $41(6 ; 30-54)$ & $151(19 ; 118-193)$ \\
2015 & $71(10 ; 53-94)$ & $51(9 ; 37-72)$ & $45(7 ; 33-61)$ & $167(23 ; 128-218)$ \\
& & & & \\
\hline
\end{tabular}

mates of distinctive MHI false killer whale abundance in the sampled area from 2000 to 2015 . These estimates appear to be robust to some forms of sampling variability and bias (Fig. 4). Specifically, sensitivity analyses using subsets of data that were consistently collected by 1 research group (CRC) over the full study period, or more reliably assembled by multiple contributors over the latter half (2008-2015), produced results that are similar to the full estimation (Fig. 4A,B). Likewise, sensitivity analyses aimed at reducing the effect of temporal and spatial variability in sampling generated estimates consistent with the main analysis (Fig. 4C,D). In addition, the increased precision and lack of outlier estimates suggest that the amount and type of recapture information in the full dataset improved and stabilized the $N_{i}$ esti- mates. Thus, the primary estimation approach can be considered a reasonable method to obtain abundance estimates of distinctive individuals using the sampled area.

While some violations of assumptions and biases could be addressed, the bias resulting from the partial sampling of the study area could not be evaluated. Thus, it is unknown to what degree the estimates of $N_{i}$ underestimate the true abundance of distinctive individuals in each year. The super-population size does estimate the total number of individuals using the sampling area during the study period, but this parameter becomes difficult to interpret biologically over long study periods because it does not reflect losses over time. Further, it does not account for individuals that never used the sampled area during the sampling periods. That is, if part of the population was never available to be sighted, perhaps because they occur only in areas that are difficult to survey (Fig. 1), then these individuals would not have been accounted for in either the $N$ or $N_{i}$ estimates. However, movement analyses of 2 of the 3 social clusters have shown that individuals satellite-tagged by CRC on the leeward sides of the MHI regularly use both leeward and windward waters throughout the chain (Baird et al. 2010, 2012), which suggests there are unlikely to be individuals in the population that never use the predominantly leeward sampling areas. Therefore, it is likely that all individuals in the population have been exposed to sampling efforts at some point during the study period, although not necessarily in each year.

Capture probability estimates for MHI false killer whales are relatively low, particularly for clusters 2 and 3, which is consistent with the low rate of CRC sightings of this population overall (Baird et al. 2013b) and for the latter 2 clusters in particular (Baird et al. 2012). The 2 best models in the POPAN estimation allowed capture probability to vary by each yearly sampling period (Table 2), indicating that annual sampling efforts and other 
ecological and environmental factors were important determinants of individual capture probabilities. However, the model that received virtually all of the quasi-Akaike weight permitted capture probability to also vary by cluster. Thus, social affiliation was a significant driver of how likely an individual was to be encountered, which corroborates ecological studies that have demonstrated clusterspecific use of the study area based on differences in movements (Baird et al. 2012) and likely exposure to threats (Baird et al. 2015). There are probably other sources of heterogeneity in capture probability that were not accounted for (e.g. survey effort), meaning that the estimates of $N_{i}$ could further underestimate the abundance of distinctive individuals (Pollock et al. 1990). In addition, ongoing analyses of network modularity suggest that MHI false killer whales may associate in more than 3 social clusters (Baird et al. 2012, R. W. Baird unpubl. data), which will be important to account for in future abundance estimations.

Although survival estimates are lacking for many odontocete species, including false killer whales, the constant survival estimate from the POPAN analysis and the model-averaged survival estimates by cluster from the CJS estimation are on par in magnitude with estimates from studies of common bottlenose Tursiops truncatus and spinner Stenella longirostris dolphins (e.g. Wells \& Scott 1990, Silva et al. 2009, Tyne et al. 2014) and of killer Orcinus orca and shortfinned pilot Globicephala macrorhynchus whales (e.g. Olesiuk et al. 1990, Alves et al. 2015). While the best CJS model specified a constant survival rate, $\mathrm{QAIC}_{\mathrm{c}}$ results indicate cluster-specific survival is also plausible. However, the available data do not support the additional model complexity, which is reflected in the overlapping $95 \%$ CIs of the survival estimates by cluster. Fisheries scarring rates of MHI false killer whales were found to differ by cluster, although not significantly, which led to the suggestion that social groups may interact with fisheries at different rates (Baird et al. 2015). The scarring rates were lowest for cluster 1 and highest for cluster 3, while the resulting survival point estimates from the cluster-varying model were highest for cluster 2 and lowest for cluster 3. However, it is premature to make inferences about the impact of fisheries on MHI false killer whale survival by cluster given the uncertainty in the survival estimates, the unquantified relationship between scarring and mortality (Baird et al. 2015), and the unknown influence of other important factors (e.g. prey fluctuations, contaminants) on survival (Oleson et al. 2010). In addition, the degree to which these estimates of apparent survival may be underestimating true survival (Schaub \& Royle 2014) has not been addressed.

Finding no significant effects of the relevant covariates on the proportion of distinctive MHI false killer whales in each CRC group, a single $\theta$ estimate was used to account for the abundance of non-distinctive individuals in the sampled area. While it is possible that the proportion of distinctive individuals does not vary as a function of these factors, the lack of significance may be a result of the relatively small number of groups evaluated. Post-hoc univariable models for Year and Frames each resulted in an $\mathrm{AIC}_{\mathrm{c}}$ value (not reported) that is within $2 \mathrm{AIC}_{\mathrm{c}}$ units of the null model, indicating these models are plausible, but not supported by the present data (Burnham \& Anderson 2002). Given the important role of $\theta$ in scaling the abundance estimate, continued monitoring of variation in the proportion of distinctive individuals in each group is recommended. The $\theta$ estimate used indicates that approximately $72 \%$ of MHI false killer whales are distinctive, which is a relatively high percentage compared with populations of spinner dolphins (e.g. $36 \%$; Tyne et al. 2014), relatively low compared with populations of bottlenose dolphins (e.g. 89\%; Ansmann et al. 2013), and more similar to populations of killer whales (e.g. 66\%; Kuningas et al. 2014). However, interpreting the magnitude of the $\theta$ estimate from this study is difficult because the proportion of distinctive individuals can vary by both species and population, and there are no $\theta$ estimates from other false killer whale populations available for comparison.

The final abundance estimates of all MHI false killer whales (distinctive and non-distinctive) in the sampled area from 2000 to 2015 (Table 6) underestimate the true population size in each year to some degree. However, the estimates suggest that the MHI false killer whale population is relatively small, which is also supported by the discovery curve of distinctive individuals (Fig. 3B). That is, the number of previously unidentified distinctive individuals encountered each year decreased substantially over the study period, further indicating that most MHI false killer whales have been exposed to sampling efforts at some point over the course of the study period, although they are not necessarily accounted for in each year due to sampling limitations. Also, some previously unidentified distinctive individuals encountered in a given year likely represent new recruits to the distinctive portion of the population. Given the reasonably assumed but unquantified impact of sampling bias, the $\mathrm{N}_{\text {total, } i}$ estimates should not be used to estimate trends in abundance. 
A survey design that systematically sampled the study area at more comprehensive and consistent temporal and spatial scales would be an effective way to obtain less biased estimates of $N_{\text {total, } i \text { that }}$ could be used to evaluate population trends. Unfortunately, the realities of funding constraints, competing research priorities, low sighting rates, and consistent trade wind conditions mean that implementing such a recommendation over the long-term would be difficult. A more sensible strategy may be to adapt or develop analytical methods that appropriately overcome limitations in the data. For example, an evaluation of movement data from satellite-tagged individuals relative to survey effort may allow the bias in the POPAN abundance estimates to be quantified or could inform other mark-recapture approaches, including spatially explicit capture-recapture methods (Borchers 2012).

In the meantime, the present POPAN estimation framework offers a readily implemented tool that uses data that have been regularly collected each year to produce current estimates of MHI false killer whale abundance that will better inform management of the population under the ESA and MMPA. For example, the last abundance estimate in the time series can be used to determine $N_{\min }$ and thus PBR for each annual review of the MHI false killer whale SAR. The $N_{\min }$ computed from the POPAN abundance estimate offers an improvement to the $N_{\min }$ based on catalog size that was previously applied because the former applies to a single year, is less sensitive to temporal variation in sampling, and accounts for non-distinctive individuals. In the 2015 SAR, the $N_{\text {min }}$ of 92 based on 2010-2014 catalog size (Carretta et al. 2016) is smaller than the $N_{\min }$ of 149 calculated from the $2015 N_{\text {total, } i}$ estimate. This increase in $N_{\min }$ increases the PBR from 0.18 (or one individual every $5.6 \mathrm{yr}$ ) to 0.30 (or one individual every $3.3 \mathrm{yr}$ ). Such improvements, even when incremental, allow for more targeted and precise management of the population.

Despite the impact of sparse data and sampling biases on the present estimates of MHI false killer whale abundance, the magnitude of these estimates (less than 200 individuals) emphasizes the endangered status of this population and its vulnerability to existing threats (Oleson et al. 2010). Ultimately, data resulting from monitoring endangered populations are rarely without limitations. However, the appropriate use of the best available data, in which bias, uncertainty, and limits of the data are addressed, provides scientists and managers with a path forward in conservation and management planning.
Acknowledgements. CRC acknowledges the large number of staff and volunteers who have assisted with field work and the US Navy for providing funding for a number of field projects where false killer whales were sighted, as well as the Hawaii Ocean Project, Hawaiian Islands Humpback Whale National Marine Sanctuary, the John F. Long Foundation, the M.B. \& Evelyn Hudson Foundation, and the Pacific Islands and Southwest Fisheries Science Centers for additional support. Studies of MHI false killer whales have been greatly enhanced thanks to individuals who contributed photos, including Jesie Abirached, Laurie Anderson, Jim Ault, Chuck Babbitt, Andrea Bendlin, Max Block, Chris Cilfone, Bo Pardau, James Begeman, Hannah Bernard, Rachel Cartwright, Jessica Chen, Phillip Colla, Colin Cornforth, Mark Deakos, Alicia Franco, Adam Frankel, members of the Hawaii Marine Mammal Consortium, Paul Johnson, Rebecca Johnston, Brett LeMaster, Ed Lyman, Jeff McConnel, Katelyn McLeod, Chad Mercer, Brandon Micek, Kim New, David Nikisher, Steve O'Toole, Doug Perrine, Dan Salden, Itana Silva, Peggy Stapp, Julie Steelman, Alison Stimpert, Chris Turner, Julian Tyne, Katie Velasquez, Deron Verbeck, Alexa Vitek, Sean Walsh, Jim Ward, Kimberly Wood, Danielle Woodward, and Ann Zoidis. The CRC surveys were conducted under permit nos. 7311509, 731-1774, and 15330. This manuscript has been improved by reviews from Jeff Laake, Nancy Young, and 3 anonymous reviewers.

\section{LITERATURE CITED}

Acevedo-Gutierrez A, Brennan B, Rodriguez P, Thomas M (1997) Resightings and behavior of false killer whales (Pseudorca crassidens) in Costa Rica. Mar Mamm Sci 13: 307-314

Akaike H (1973) Information theory and an extension of the maximum likelihood principle. In: Petrov BN, Csàki F (eds) Second Int Symp on Information Theory. Akademiai Kiàdo, Budapest, p 267-281

Altukhov AV, Andrews RD, Calkins DG, Gelatt TS and others (2015) Age-specific survival rates of Steller sea lions at rookeries with divergent population trends in the Russian Far East. PLOS ONE 10:e0127292

Alves F, Dinis A, Nicolau C, Ribeiro C, Kaufmann M, Fortuna C, Freitas L (2015) Survival and abundance of shortfinned pilot whales in the archipelago of Madeira, NE Atlantic. Mar Mamm Sci 31:106-121

Anderson DR, Burnham KP, White GC (1994) AIC model selection in overdispersed capture-recapture data. Ecology 75:1780-1793

Ansmann IC, Lanyon JM, Seddon JM, Parra GJ (2013) Monitoring dolphins in an urban marine system: total and effective population size estimates of Indo-Pacific bottlenose dolphins in Moreton Bay, Australia. PLOS ONE 8: e65239

Baird RW (2018) False killer whale: Pseudorca crassidens. In: Würsig B, Thewissen JGM, Kovacs KM (eds) Encyclopedia of marine mammals, 3rd edn. Academic Press, San Diego, CA, p 347-349

Baird RW, Gorgone AM, Webster DL, McSweeney DJ and others (2005) False killer whales around the main Hawaiian Islands: an assessment of inter-island movements and population size using individual photo-identification. Report prepared under Order No. JJ133F04SE0120 from the Pacific Islands Fisheries Science Center, National Marine 
Fisheries Service. www.cascadiaresearch.org/robin/Baird \%20et\%20al\%202005\%20Hawaii\%20Pseudorca.pdf

Baird RW, Gorgone AM, McSweeney DJ, Webster DL and others (2008) False killer whales (Pseudorca crassidens) around the main Hawaiian Islands: long-term site fidelity, inter-island movements, and association patterns. Mar Mamm Sci 24:591-612

Baird RW, Schorr GS, Webster DL, McSweeney DJ, Hanson MB, Andrews RD (2010) Movements and habitat use of satellite-tagged false killer whales around the main Hawaiian Islands. Endang Species Res 10:107-121

Baird RW, Hanson MB, Schorr GS, Webster DL and others (2012) Range and primary habitats of Hawaiian insular false killer whales: informing determination of critical habitat. Endang Species Res 18:47-61

Baird RW, Oleson EM, Barlow J, Ligon AD, Gorgone AM, Mahaffy SD (2013a) Evidence of an island-associated population of false killer whales (Pseudorca crassidens) in the Northwestern Hawaiian Islands. Pac Sci 67: 513-521

Baird RW, Webster DL, Aschettino JM, Schorr GS, McSweeney DJ (2013b) Odontocete cetaceans around the main Hawaiian Islands: habitat use and relative abundance from small-boat sighting surveys. Aquat Mamm 39:253-269

Baird RW, Mahaffy SD, Gorgone AM, Cullins T and others (2015) False killer whales and fisheries interactions in Hawaiian waters: evidence for sex bias and variation among populations and social groups. Mar Mamm Sci 31:579-590

Borchers D (2012) A non-technical overview of spatially explicit capture-recapture models. J Ornithol 152: 435-444

Bradford AL, Wade PR, Weller DW, Burdin AM and others (2006) Survival estimates of western gray whales Eschrichtius robustus incorporating individual heterogeneity and temporary emigration. Mar Ecol Prog Ser 315:293-307

Bradford AL, Oleson EM, Baird RW, Boggs CH, Forney KA, Young NC (2015) Revised stock boundaries for false killer whales (Pseudorca crassidens) in Hawaiian waters. NOAA Tech Memo, NOAA-TM-NMFS-PIFSC-47

Burnham KP, Anderson DR (2002) Model selection and multimodel inference: a practical information-theoretic approach, 2nd edn. Springer-Verlag, New York, NY

Burnham KP, Anderson DR, White GC, Brownie C, Pollock KH (1987) Design and analysis methods for fish survival experiments based on release-recapture. Am Fish Soc Monogr 5, Bethesda, MD

Carretta JV, Oleson EM, Baker J, Weller DW and others (2016) U.S. Pacific marine mammal stock assessments: 2015. NOAA Tech Memo NOAA-TM-NMFS-SWFSC561

Chivers SJ, Baird RW, McSweeney DJ, Webster DL, Hedrick NM, Salinas JC (2007) Genetic variation and evidence for population structure in eastern North Pacific false killer whales (Pseudorca crassidens). Can J Zool 85: 783-794

Chivers SJ, Baird RW, Martien KM, Taylor BL and others (2010) Evidence of genetic differentiation for Hawai'i insular false killer whales (Pseudorca crassidens). NOAA Tech Memo NOAA-TM-NMFS-SWFSC-458

Cormack RM (1964) Estimates of survival from the sighting of marked animals. Biometrika 51:429-438

* Hurvich CM, Tsai CL (1989) Regression and time series model selection in small samples. Biometrika 76:297-307

Jolly GM (1965) Explicit estimates from capture-recapture data with both death and immigration-stochastic model. Biometrika 52:225-247

Joly JL, Reynolds J, Robards M (2010) Recognizing when the 'best scientific data available' isn't. Stanf Environ Law J 29:247-282

Kasuya T (1996) False killer whales. In: Tamura T, Ohsumi $\mathrm{S}$, Arai S (eds) Report of investigation in search of solution for dolphin-fishery conflict in the Iki Island areas. Japan Fisheries Agency, Tokyo, p 178-187

Kendall WL, Nichols JD, Hines JE (1997) Estimating temporary emigration using capture-recapture data with Pollock's robust design. Ecology 78:563-578

Kuningas S, Similä T, Hammond PS (2014) Population size, survival and reproductive rates of northern Norwegian killer whales (Orcinus orca) in 1986-2003. J Mar Biol Assoc UK 94:1277-1291

Laake JL (2013) RMark: an R interface for analysis of capture-recapture data with MARK, AFSC Processed Report 2013-01

* Lebreton JD, Burnham KP, Clobert J, Anderson DR (1992) Modeling survival and testing biological hypotheses using marked animals: a unified approach with case studies. Ecol Monogr 62:67-118

* Martien KK, Chivers SJ, Baird RW, Archer FI and others (2014) Nuclear and mitochondrial patterns of population structure in North Pacific false killer whales (Pseudorca crassidens). J Hered 105:611-626

*Mobley JR Jr (2004) Results of marine mammal surveys on U.S. Navy underwater ranges in Hawaii and Bahamas. Final Report to Office of Naval Research, Marine Mammal Program. www.dtic.mil/dtic/tr/fulltext/u2/a421 488.pdf

*Murphy DD, Weiland PS (2016) Guidance on the use of best available science under the U.S. Endangered Species Act. Environ Manage 58:1-14

Nichols JD (2005) Modern open-population capture-recapture models. In: Amstrup SC, McDonald TL, Manly BFJ (eds) Handbook of capture-recapture analysis. Princeton University Press, Princeton, NJ, p 88-123

Olesiuk PF, Bigg MA, Ellis GM (1990) Life history and population dynamics of resident killer whales (Orcinus orca) in the coastal waters of British Columbia and Washington State. Rep Int Whal Comm Spec Issue 12:209-243

Oleson EM, Boggs CH, Forney KA, Hanson MB and others (2010) Status review of Hawaiian insular false killer whales (Pseudorca crassidens) under the Endangered Species Act. NOAA Tech Memo NOAA-TM-NMFSPIFSC-22

* Palmer C, Baird RW, Webster DL, Edwards AC and others (2017) A preliminary study of the movement patterns of false killer whales (Pseudorca crassidens) in coastal and pelagic waters of the Northern Territory, Australia. Mar Freshw Res 68:1726-1733

*Pollock KH (1982) A capture-recapture design robust to unequal probability of capture. J Wildl Manag 46: $752-757$

Pollock KH (2000) Capture-recapture models. J Am Stat Assoc 95:293-296

Pollock KH, Alpizar-Jara R (2005) Classical open-population capture-recapture models. In: Amstrup SC, McDonald TL, Manly BFJ (eds) Handbook of capture-recapture analysis. Princeton University Press, Princeton, NJ, p 36-57 Pollock KH, Nichols JD, Brownie C, Hines JE (1990) Statisti- 
cal inference for capture-recapture experiments. Wildl Monogr 107:3-97

R Core Team (2016) R: a language and environment for statistical computing. R Foundation for Statistical Computing, Vienna

Reeves RR, Leatherwood S, Baird RW (2009) Evidence of a possible decline since 1989 in false killer whales (Pseudorca crassidens) around the main Hawaiian Islands. Pac Sci 63:253-261

Schaub M, Royle JA (2014) Estimating true instead of apparent survival using spatial Cormack-Jolly-Seber models. Methods Ecol Evol 5:1316-1326

Schwarz CJ, Arnason AN (1996) A general methodology for the analysis of capture-recapture experiments in open populations. Biometrics 52:860-873

Schwarz CJ, Seber GAF (1999) Estimating animal abundance: review III. Stat Sci 14:427-456

Seber GAF (1965) A note on the multiple-recapture census. Biometrika 52:249-259

Seber GAF (1982) The estimation of animal abundance and related parameters, 2nd edn. Macmillan, New York, NY

Seber GAF (2001) Some new directions in estimating animal population parameters. J Agric Biol Environ Stat 6: $140-151$

Silva MA, Magalhães S, Prieto R, Santos RS, Hammond PS (2009) Estimating survival and abundance in a bottlenose dolphin population taking into account transience and temporary emigration. Mar Ecol Prog Ser 392:263-276

Tyne JA, Pollock KH, Johnston DW, Bejder L (2014) Abundance and survival rates of the Hawai'i Island associated spinner dolphin (Stenella longirostris) stock. PLOS ONE 9:e86132

Editorial responsibility: Simon Goldsworthy, West Beach, South Australia, Australia
Urian K, Gorgone A, Read A, Balmer B and others (2015) Recommendations for photo-identification methods used in capture-recapture models with cetaceans. Mar Mamm Sci 31:298-321

WWade PR (1998) Calculating limits to the allowable humancaused mortality of cetaceans and pinnipeds. Mar Mamm Sci 14:1-37

* Weir CR, Collins T, Cross T, Gill A, Elwen S, Unwin M, Parnell RJ (2013) False killer whale (Pseudorca crassidens) sightings in continental shelf habitat off Gabon and Côte d'Ivoire (Africa). Mar Biodivers Rec 6:e65

Wells RS, Scott MD (1990) Estimating bottlenose dolphin population parameters from individual identification and capture-release techniques. Rep Int Whal Comm Spec Issue 12:407-415

White GC (2008) Closed population estimation models and their extensions in program MARK. Environ Ecol Stat 15: 89-99

White GC, Burnham KP (1999) Program MARK: survival estimation from populations of marked animals. Bird Study 46(Suppl):S120-S139

Williams BK, Nichols JD, Conroy MJ (2002) Analysis and management of animal populations, Academic Press, San Diego, CA

*Wilson B, Hammond PS, Thompson PM (1999) Estimating size and assessing trends in a coastal bottlenose dolphin population. Ecol Appl 9:288-300

* Zaeschmar JR, Visser IN, Fertl D, Dwyer SL and others (2014) Occurrence of false killer whales (Pseudorca crassidens) and their association with common bottlenose dolphins (Tursiops truncatus) off northeastern New Zealand. Mar Mamm Sci 30:594-608

Submitted: June 14, 2017; Accepted: May 16, 2018

Proofs received from author(s): August 7, 2018 